\title{
Hirschi Kevin
}

International Black Sea University, Georgia

\section{Intonation and Word Stress in Georgian EFL Learners' Utterances: does Praat Training Help?}

\begin{abstract}
For EFL speakers, prosodic features such as intonation and word stress contribute greatly to the comprehensibility of an utterance (Derwing \& Rossiter, 2003; Zielinski, 2008). Yet, many of the problems learners face in being understood may be due to L1 - L2 transfer of these prosodic features (Flege, 1984). While some phonological research has been done on Georgian speakers speaking in Georgian (Alkhazishvili, 1959; Skopeteas, Féry, \& Asatiani, 2008), little is known about L1 - L2 phonological transfer in Georgian EFL learners' utterances in English. Additionally, no known study has used Praat training with Georgian EFL speakers to increase the awareness of intonation and word stress in English and improve the intelligibility of their utterance. This study investigated L1 - L2 transfer in word stress and intonation of speech collected during a freespeaking activity from several Georgian EFL learner participants. Based on examples in the recordings, five problematic words and five problematic phrases in English were identified as target forms for a three-week pronunciation training that focused on intonation and word stress with Praat with the same six participants. Recordings before and after pronunciation training will be collected and analyzed to investigate modifications made by the participants. Results indicate a statistically significant improvement in word stress, however a non-significant change in intonation. While certain features of L1 - L2 transfer in word stress and intonation are present in the data, they do not match exactly the tendency of Georgian speakers. Implications are made for pronunciation teachers of Georgian learners as well as teachers with learners of other languages that face similar prosodic differences.
\end{abstract}

Key words: Phonology, Pronunciation, Praat, Georgian, Prosody.

\section{Introduction}

Learning and speaking a foreign language involves a vast variety of skills including a knowledge and ability to use, in production, lexical items through appropriate syntax; an understanding of the pragmatic implications of the language; and, of course, the ability and knowledge to use specific sounds to communicate. Phonology, the study of the interpretation of the sounds of a language, is a part of all learner's process of acquiring a language. Traditional approaches to learning English L2 learner's deviations, progress, and instruction in producing and perceiving segmental sounds, i.e., individual phonemes; however, there a growing focus on suprasegmental features, such as sentence prominence, rhythm, features of connected speech (such as liaison and elision), word stress (also known as lexical stress), and intonation (e.g., Derwing \& Munro, 1997; Derwing \& Rossiter, 2003; Gorjian, Hayati, \& Pourkhoni 2013; Levis \& Pickering, 2004).

This article focuses on two suprasegmental features, intonation and word stress, to determine the impact of visual-explicit instruction, integrated technology, and features in participants' native language in the acquisition of target forms in English. It recognizes that word stress and intonation are typically associated with the native 
speaker of English (NSE) norms in varieties of English (i.e., Received Pronunciation, General American, and South Asian English) and is not considered an integral part of English as a Lingua Franca (Jenkins, 2000). However, it is nonetheless an area of interest as learners express the desire to check their mastery of phonological features as they balance control of accuracy and fluency when learning a new language and to be able to communicate well with NSEs. It is particularly novel in the use of participants who are native speakers of Georgian, a Kartvelian language in the South Caucuses.

\section{Intonation}

Intonation is the use of pitch to convey supra-lexical information such as emotions, focus, and signals of questions. In English, there is considerable difference in intonation norms amongst genders, varieties of English, and individuals. The general categories of intonation patterns that are somewhat stable amongst users are declarative statements, polar questions (yes / no), and information questions. Among these, the possible intonation contours that have been found are analyzed at the terminus as falling, low rising, and high rising (Cutler, 2005; Fletcher, Grabe, and Warren, 2006; Fries, 1964; Ogden, 2009; Roach, 1982). The intonation choices by speakers is often pragmatic: they can modify the illocutionary force to check for clarification, or express shock and disbelief.

Amongst L2 leaners of English, practitioners have combined intonation training with rhythm, sentence prominence, and other features in creative ways such as kazoos (Gilbert, 1978) and traditional textbook materials (Hancock, 2003; Lane, 2005). Classroom instruction models have been formed and recommend instructors to follow a model of analysis, listening discrimination, controlled practice, guided practice, and communicative activities (Celce-Murcia, Brinton \& Goodwin, 2010). There is, however, extensive discussion over the importance of the feature and instruction of intonation, in particular in EFL contexts. Jenkins (2000) posits that intonation contours and their pragmatic meaning, are tied to NSE populations; i.e., there are NNSE groups that create their own alternative intonation pragmatics. Therefore, instruction time is better spent on other issues.

\section{Word Stress}

The English phonological system contains a variable stress for syllables within words. Often called lexical stress, word stress is phonemic, i.e., it can differentiate between two separate words. While many words do not

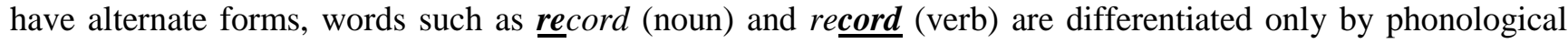
stress. When this occurs, weak sounds are often modified to a shwa. For the vast majority of words in English, word stress is lexical and must be learned along with the word. This is a challenge mastered by nearly all NSs of English, but can prove challenging for Non-Native Speakers of English (NNSEs), a phenomenon long studied by those concerned with pronunciation (Newman, 1946).

Word stress is important for NS to understand NNS as confirmed by both studies in psycholinguistics and cognitive science. Bond (1999) found evidence to support an argument that NS of English listen more closely to stressed syllables than to unstressed syllables. Therefore, not only may the location of the stress within the word be important, but the phonemic quality may contribute as to comprehension as well. Other researchers view lexical items as if they exist in a database. If this is the case, the index for finding a word, its meaning, and other information, is the stressed syllable (Grosjean \& Gee, 1987).

Further evidence from the field of applied linguistics has confirmed that the intelligibility of an utterance relies at least partially on word stress (Zielinski, 2008). This has led to empirically-based recommendations and examples of intervention studies that include word stress to promote intelligibility (Derwing \& Munro, 1997; Derwing \& Rossiter, 2003; Munro \& Derwing, 1995). While much of these studies show improvement and partial importance of the correct stress of a syllable, they find that the segmental quality of the stressed syllable is of greater importance for intelligibility by NSE raters. However, Field (2005), found that NSEs responded to 
intelligibility ratings in similar ways as NNSEs. None of the studies found include Georgian participants or participants from Kartvelian languages.

\section{Georgian Lanugage}

Georgian intonation is quite different from that found in English. As it is a synthetic language with flexible word order, the intonation contour of a declarative can vary greatly from utterance to utterance. Skopeteas, Féry, and Asatiani (2009) and Jun, Vicenik, and Lofstedt (2007) both describe several instances of a falling phrasal terminal. However, questions seem to vary greatly based on the focus of the question. A strong rise and fall, and sometimes a second rise and fall, seem to be common in polar (yes / no) questions. This allows the speaker many choices. A focus word can be moved to the beginning of the sentence, the end of the sentence, or kept anywhere with additional intonation emphasis. Similarly, information (wh-) questions seem to have an intonation focus on the wh- question word. Figure 1 illustrates this in the sentence whom is Nino looking after?

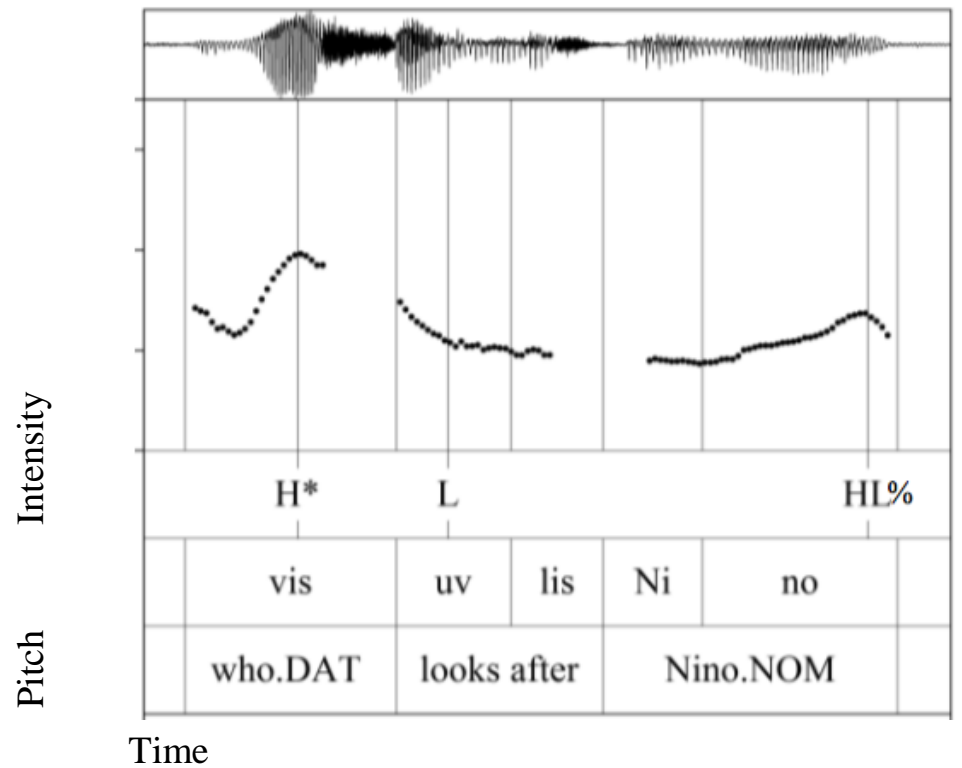

Figure 1. Prominence and rising intonation on question word in Georgian utterance (Borise, 2017, p. 94).

Georgian is also a fixed-stress language with some exceptions. Early research on the language reported that there was a fixed stress on the first syllable of each word (Alkhazishvili, 1959). However, more recent studies have painted a picture that is a bit more complex. The Georgian language is synthetic. Verbs, in particular, can be modified with prefixes, infixes, and suffixes. Recent studies have found that the stressed syllable can be the antepenult in some cases (Butskhrikidze, 2002; Butskhrikidze, 2016; Jun et al., 2007).

The present study endeavors to investigate the phonological features of Georgian NNSEs. Two areas of focus are targeted: intonation in three types of phrases (declaratives, polar questions, and information questions), and word stress. These were chosen because of anecdotal evidence encountered by the research as well as the amount of information known about their Georgian language equivalents that will allow for crosslanguage comparison. In addition, this study will investigate the impact of Praat training in these two phonological areas. While several practitioners report settings where learners use Praat (Wilson, 2008), no known studies have done so with L1 Georgian learners. Therefore, the following research questions were formed:

1. To what extent does Praat help learners match target features in sentence intonation based on models?

2. To what extend does Praat help learners match word stress patterns based on models?

3. Are learners' utterances similar to Georgian phonology? 


\section{Hypotheses}

The results of the first and second research questions regarding intonation and word stress are expected to reveal that learners, given feedback from Praat, are able to improve their ability to control intonation and word stress and match their targeted forms. Based on research reviewed above, several techniques have been used with both simple resources, such as Gilbert's (1979) Kazoos and, with Praat and other computer platforms, such as Wilson's (2008) guidelines. However, the extent to which training in intonation can impact a learners' ability to control the said variable in production is unknown.

The third research question is exploratory in nature. As such, it is unknown which features may be transferred from learner's L1 to production samples collected during this study. As word stress is relatively fixed in Georgian, it is possible that this feature is transferred to English utterances by participants. However, there is ample evidence that learners overcome this even without explicit instruction on word stress. It is also expected that intonation issues will be transferred, but exactly how is not known.

\section{Method \\ Introduction}

The first two research questions, regarding learners using Praat to match target forms of intonation and word stress, are addressed in an intervention study. Data was collected, normed, and both descriptive and inferential statistics were computed. For the final research question, selected samples were closely analyzed to find tendencies and trends in the data. The description of the analysis is in the following sections on participants in the study, materials used to collect data and during the intervention, a detailed account of the procedures and an outline of the steps of the analysis.

\section{Participants}

Six Georgian learners of English were selected from an intact group of second year students at a university in the capital of Georgia. The participants were all female aged 18-20, which is representative of the population of English majors at the university. Students of this program are required to have the proficiency of preintermediate in English during admissions and are expected to master English to an advanced level. The study program includes two semesters of pronunciation and listening courses as well as a variety of other speaking skills courses and general English language skills courses. The native language of students in this program is not homogenous, however all participants are native speakers of Georgian. Only four of the six participants completed the entire course and the post-semester Praat lab workshop.

\section{Materials}

This study included resources from textbooks, pronunciation training websites, and computer software. Two textbooks were used in the courses of pronunciation training, both of which include lessons in word stress and intonation. Lane's (2005) textbook offers four units on word stress and two units on intonation. Units 18 and 19 (strong stress and secondary, Weak syllables, respectively) were used as a part of the course in classroom lectures. Units 27 and 28 (rising and falling intonation, using your voice to show your feelings, respectively) were used for intonation instruction as well. In addition, students were required to create pronunciation practice stations for a rotating final course assignment, in which lessons 28 - 31 and 54 - 60 were from Hancock (2003) and were options. Students chose lessons 28 (stress in two syllable words), 29 (stress in compound words), 56 (tones in asking for information), and 59 (agreeing and disagreeing tones). While all of 
E ISSN 1512-3146 (online) ISSN 1987-9601 (print)
International Journal

of Multilingual Education

the participants for the current study were present, they may not have all seen each other's pronunciation stations.

In addition to these textbook resources, participants completed lessons on Seattle Learning Academy's (2016) Pronuncian website <http://pronuncian.com>. Lessons included word stress and intonation.

Instructors of pronunciation often deliver explicit instruction in prosodic features for adolescent and adult second and foreign language learners. To assist in explicit understanding of prosodic features, computers have been used to analyze recorded speech and visually display pitch contour and intensity contour of the sound. Praat is one such software that has been adapted from phonetics research to classroom use (Boersma, 2001; Wilson, 2008). Praat was also used in the classroom and in the post-semester lab workshop.

\section{Procedures}

Before pronunciation training, speaking samples recorded by participants at home were recorded and submitted to an online platform. Samples included responses to questions asked at the end of a lecture that included related vocabulary instruction, a reading or listening passage, and in-class practice speaking on the same topic. The researcher collected eight samples from six participants to serve as a pre-treatment baseline for intonation and to collect common errors in word stress.

During the course of the semester, Praat was introduced and was used to show and check student performance of a variety of phonological features, including word stress and intonation. Students volunteered to record themselves saying a phrase and show the Praat analysis to the class. This was done for instructor-led units on both intonation and word stress.

At the end of the semester, four participants completed additional training in a lab with Praat using the Seattle Learning Academy's (2016) Pronuncian website for approximately two hours. The first part of this lesson was a baseline recording of a list of 15 different target items. For intonation, there were a variety of sentence fragments, short declarative sentences, wh - questions, and yes / no questions. Participants were then guided through print explanations of common practices in intonation and word stress and provided with several examples. They were then given printed Praat analyses of sample audio files and were asked to match pitch contour, in the case of the intonation lesson, or intensity contour, in the case of the word stress lesson, as closely as possible.

After completing the intensive section of the lesson, participants were then instructed to create a speech that included five target forms from the pronunciation lesson that was practiced. Several recordings were kept during the process of comparing participant speech to target models in Praat which were marked by the participants as an attempt or a final submission for matching a target form of intonation or word stress. The final, semi-spontaneous speech and the participants' choices of their final submission were used for posttreatment data.

Research ethics protocols in informed consent were followed. Participants agreed to allow their speech files and handouts to be used for this study. Participants were also informed of their right to end their participation in this study at any time. 


\section{Analysis}

All speech files required cleaning for noise through sound editing software. The pre-treatment speech and post-treatment speech were initially transcribed automatically and then checked by the researchers manually. The researcher checked the accuracy of transcription and counted the number of sentences, marking each as an intonation token. In addition, multisyllabic words were coded for normalized comparison of word stress. Sentence boundaries were determined by intonation and rhythm, rather than grammatical or organizational features. Each token was coded as one of the three types of targeted intonation; declarative, wh- questions, and yes / no questions. Figure 2 illustrates pitch and intensity contours of an utterance marked with incorrect word stress on the word percent and accurate falling intonation that marked the end of declarative sentences.

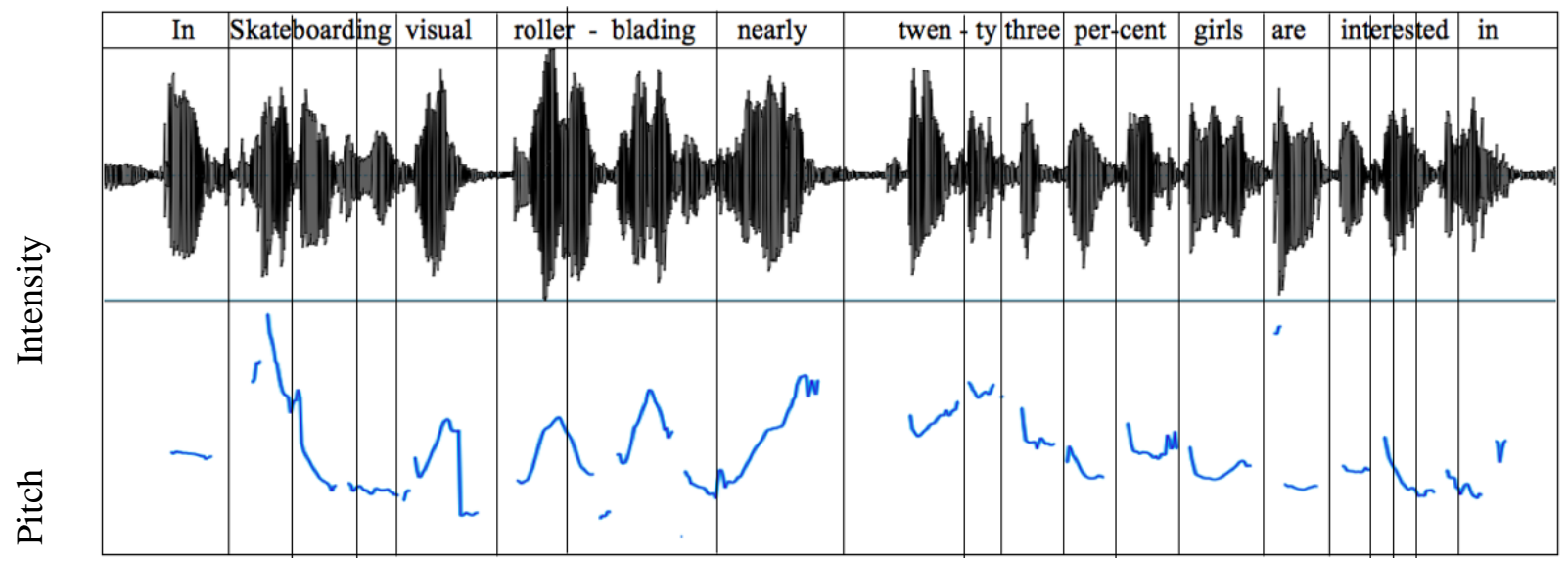

Time

Figure 2. Sentence intonation of declarative sentence illustrating falling sentence terminal and incorrect stress on percent.

The researcher used intensity waveform displays and pitch contours in Praat to mark errors in word stress and unexpected intonation across the three types of intonations. The number of unexpected intonation tokens was divided by the total number of intonation tokens for each sample to create a score that was comparable across samples with different numbers of tokens. Both General American and Received Pronunciation word stress patterns were considered acceptable.

Due to the limited number of target forms of intonation in the three types investigated by this study (declaratives, wh-questions, and yes/no questions), pre-treatment totals included both the pre-treatment speech collected at the beginning of the semester and items elicited at the beginning of the Praat lab training.

To address the third research question, participant samples of unexpected or incorrect intonation and word stress were used and compared to research by Jun et al. (2007) and Skopeteas et al. (2009). These studies include one female Georgian NS in her 50s in North America and sixty Georgian NS in the capital of Georgia. Using Praat, side-by-side comparisons of intonation spectrum readouts and word stress.

\section{Results}

The results section is divided by research question. The first section pertains to participant data analysis for intonation. The second is for word stress. For the first and second research question, token and word counts are given before descriptive and inferential statistics for accuracy. The third research question uses several examples from participant data and phonological research on Georgian utterances to compare features. 


\section{Intonation}

Intonation data was compiled from four sources: (a) the pre-treatment, beginning of semester speech, (b) the elicited list of target items, (c) the targeted items marked by participants during the Praat lab lesson and (d) the post-treatment spontaneous speech. Each sentence, as determined by intonation, was considered a token. The average length of the pre-treatment, beginning of semester speech transcript was 23 sentences $(S D=7.78)$. Each participant read 18 phrases at the beginning of the Praat lab lesson and 10 during the lesson. The posttreatment speeches were shorter, the average length of the transcript being and 8.75 sentences $(S D=1.79)$. See Table 1 for complete token data.

Table $1 \quad$ Distribution of targeted intonation tokens for all participants across procedures

\begin{tabular}{lllll}
\hline & Declaratives & Wh-questions & Yes / No Questions & Total \\
\hline Pre-treatment speech & 92 & 0 & 0 & 92 \\
Pre-treatment elicited list & 12 & 16 & 8 & 36 \\
Post-treatment elicited list & 16 & 12 & 12 & 40 \\
Post-treatment speech & 34 & 0 & 1 & 35 \\
Total & 154 & 28 & 21 & 203 \\
\hline
\end{tabular}

Speeches and elicited lists were combined to compare treatment effects and scores were averaged based on accuracy of target feature from each sample. The results are broken down by target intonation type. For declaratives, the average pre-treatment accuracy of expected falling intonation was 71.64 (SD = 5.87). For whquestions, the average pre-treatment accuracy was $25(\mathrm{SD}=43.30)$ and for yes / no questions, the average pretreatment accuracy was $100(\mathrm{SD}=0)$. The post-treatment results for declaratives was on average $86.88(\mathrm{SD}=$ 7.85), for wh- questions was 88.89 ( $\mathrm{SD}=13.61)$, and yes / no questions had an average of $89.58(\mathrm{SD}=13.66)$. See Figure 3 for visualization of pre-treatment and post-treatment scores.

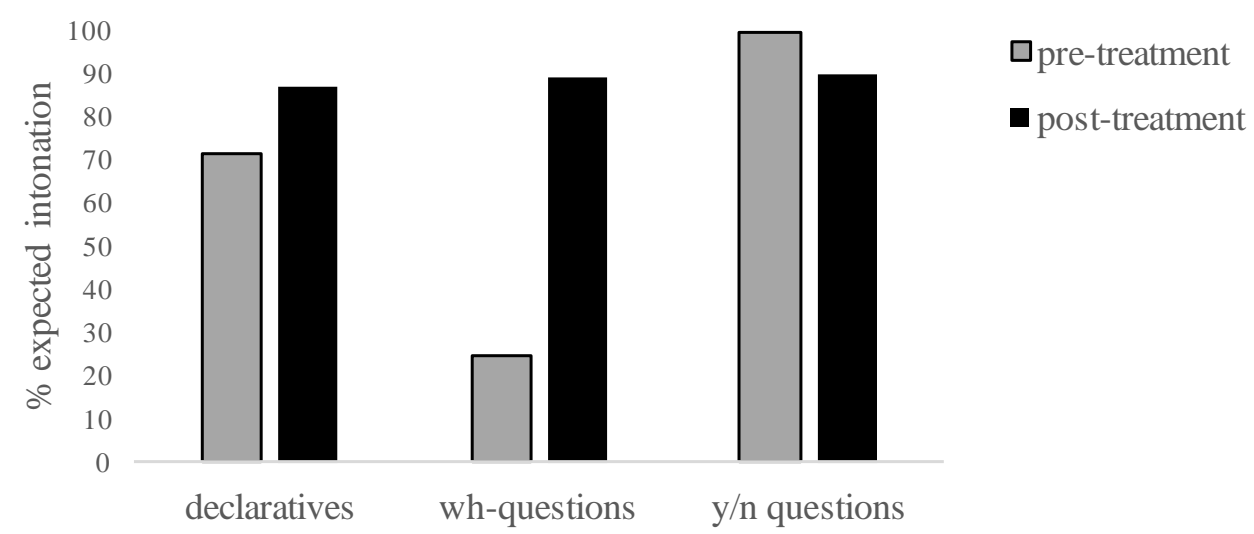

Figure 3. Pre-treatment and post-treatment averages bar chart.

All three target types were tested using a paired-samples t-test. Parametric tests were chosen despite the small sample size based on the original use of the t-test outlined by Student (1908). Inferential statistics were

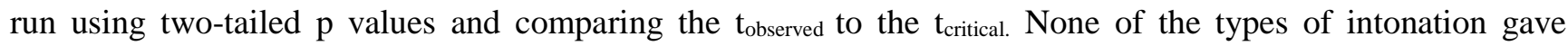
significant results. The $\mathrm{t}_{\text {observed }}$ was $\mathrm{t}=2.41,2.85$, and 1.32 for declarative, wh-questions, and yes / no questions, respectively. As the degrees of freedom were consistent across types, the $t_{\text {critical }}$ (all types) was $+/-3.18$. See Table 2 for complete results. This indicates that, with the data to hand, it is not possible to conclude that the treatment had an impact on the scores. 
Table 2 Pre-treatment and post-treatment accuracy of intonation feature

\begin{tabular}{|c|c|c|c|c|c|c|}
\hline \multirow[b]{2}{*}{ type } & \multicolumn{2}{|c|}{ Pre-treatment } & \multicolumn{2}{|c|}{ Post-treatment } & \multicolumn{2}{|c|}{ Significance } \\
\hline & tokens & $\mathrm{M}(S D)$ & tokens & $\mathrm{M}(S D)$ & $t_{\text {observed }}$ & $\mathrm{p}$ \\
\hline declarative & 104 & $71.64(5.87)$ & 50 & $86.88(7.85)$ & 2.41 & 0.01 \\
\hline wh-questions & 16 & $25(43.30)$ & 12 & $88.89(13.61)$ & 2.85 & 0.07 \\
\hline $\begin{array}{l}\text { Yes / no } \\
\text { questions }\end{array}$ & 8 & $100(0)$ & 13 & $89.58(13.66)$ & 1.32 & 0.28 \\
\hline
\end{tabular}

Note. $\mathrm{N}$ (all types) $=4, \mathrm{df}$ (all types) $=3, \mathrm{t}_{\text {critical }}$ (all types) $=+/-3.18$ (two-tailed), $\mathrm{p}<.05$

\section{Word Stress}

Word stress data was compiled from two sources: the pre-treatment, beginning of semester speech and the post-treatment spontaneous speech. Each multisyllabic word was considered a token. The average length of the pre-treatment, beginning with the semester speech transcript was 188.25 words $(S D=43.40)$. Each participant read 18 phrases at the beginning of the Praat lab lesson and 10 during the lesson. The post-treatment speeches were shorter, the average length of the transcript being 64.25 words $(S D=5.80)$. See Table 3 for complete token distribution and descriptive statistics. Figure 4 illustrates the breakdown of words and errors.

Table 3

Distribution of words multisyllabic words, and word stress errors

\begin{tabular}{lll}
\hline & Pre-treatment & Post-treatment \\
\hline total words & 753 & 256 \\
multisyllabic words & $(\mathrm{M}=188.25, \mathrm{SD}=43.40)$ & $(\mathrm{M}=23.00, \mathrm{SD}=7.78)$ \\
& 332 & 98 \\
errors in word stress & $(\mathrm{M}=83.00, \mathrm{SD}=18.36)$ & $(\mathrm{M}=24.50, \mathrm{SD}=3.04)$ \\
& 37 & 4 \\
score & $(\mathrm{M}=9.25, \mathrm{SD}=1.92)$ & $(\mathrm{M}=1.00, \mathrm{SD}=0.71)$ \\
\hline
\end{tabular}

Inferential statistics were also computed. A score was calculated based on the number of word stress errors divided by the number of multisyllabic words. A paired-samples t-test was computed from the scores. Inferential statistics were run using two-tailed $p$ values and comparing the $t_{\text {observed }}$ to the $t_{\text {critical. }}$ The results were significant. The $t_{\text {observed }}$ was $t=6.80$ and as the degrees of freedom were 3 , the $t_{\text {critical }}$ was set at $+/-3.18$ using two-tailed, $\mathrm{p}<.05$. The result was $\mathrm{p}=0.01$. Post-hoc calculations were run to find the effect size following Cohen (1988). The resulting eta ${ }^{2}$ was 0.74 , indicating that much of the improvement in scores was due to the treatment.

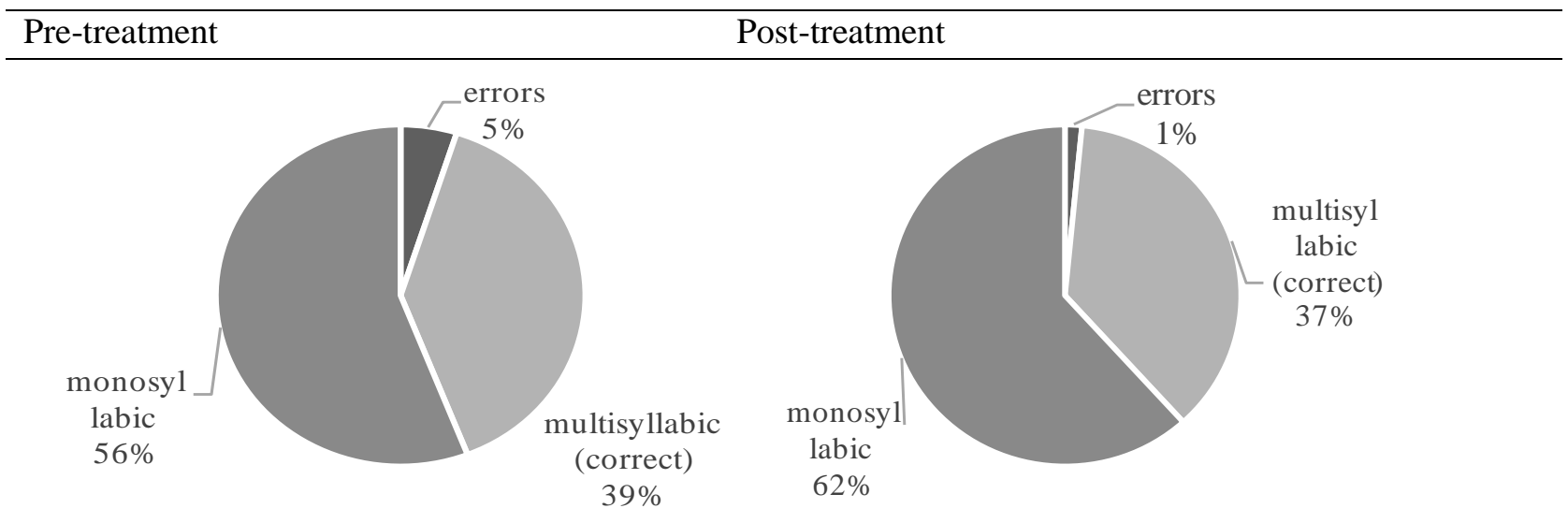

Figure 4. Side-by-side comparison of pre- and post-intervention word stress conditions. 


\section{Similarities to Georgian Phonology}

Analyses for similarities in intonation between participant samples and Georgian language utterances was conducted using Praat examples from Borise (2017) and Skopeteas et al. (2009). Comparisons of declarative sentences revealed that an intonation difference was placed on the main verb of the sentence in many utterances, however the intonation difference was not similar. In the case of this utterance in Georgian, the main verb (likes / moscons) is marked by high tones. The comparison phrase by a participant in this study in English shows a similar emphasis but is marked by low tones on the main verb (love). See Figures 5 and 6.

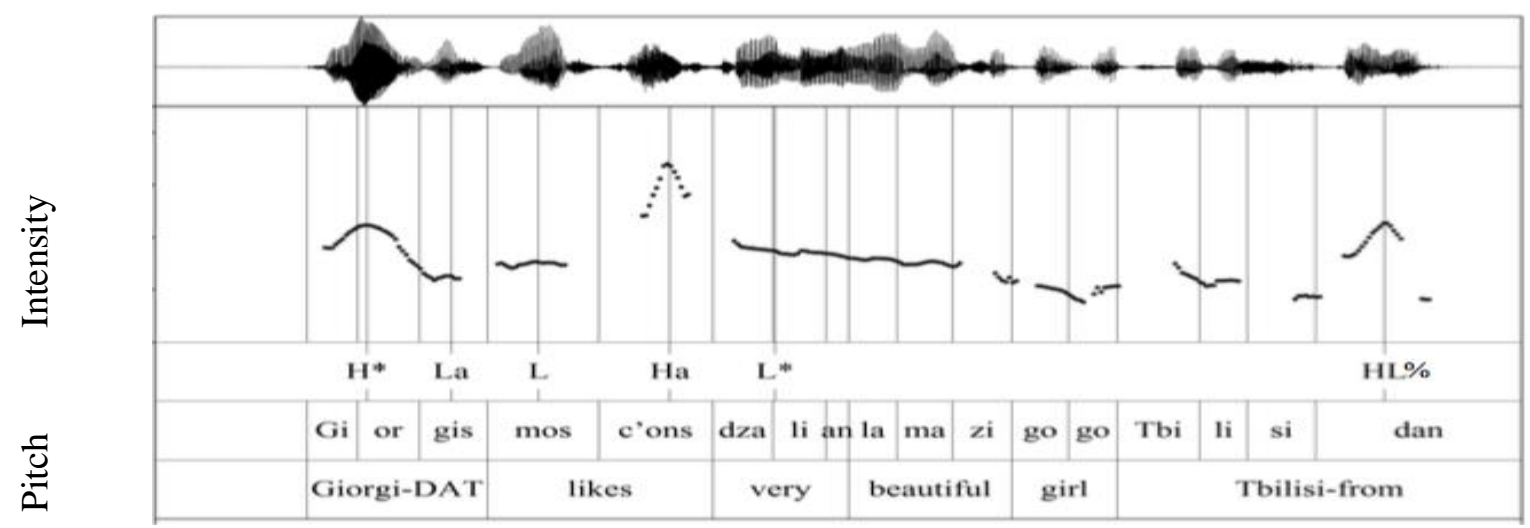

Time

Figure 5. Georgian sentence with high rising and falling tone on main verb (Borise, 2017, p. 92).

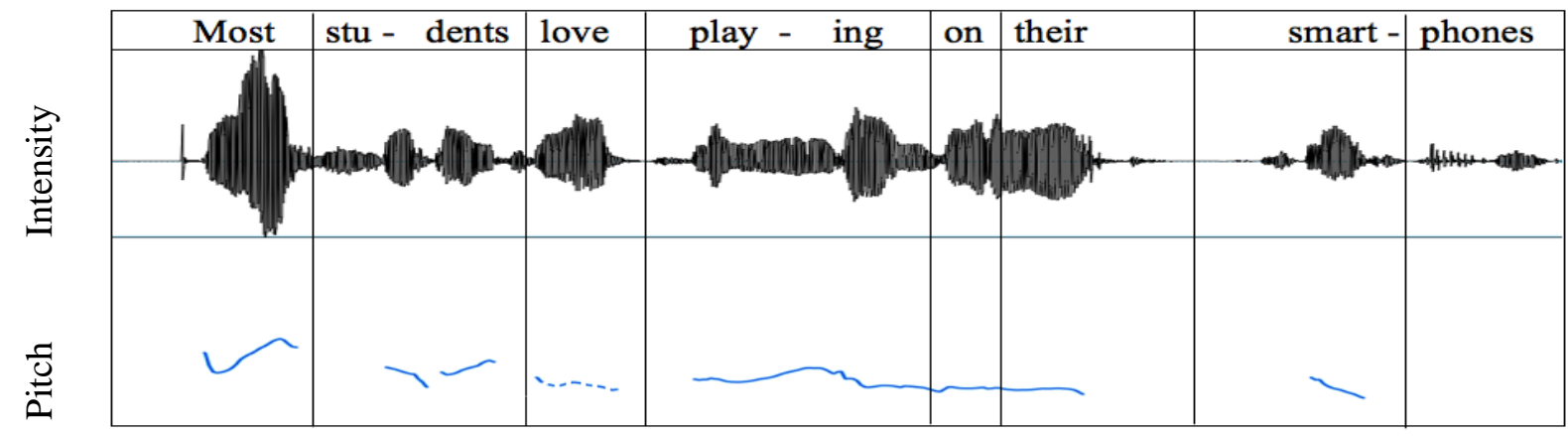

Time

Figure 6. Participant declarative sentence in English with slight intonation different on main verb.

Another theme that surfaced during the review of these sentences was the noticeable smaller amount of pitch variation. As can be seen in Figures 4 and 5, the statement in Georgian has a much wider range of pitch $(75 \mathrm{~Hz}$ to $350 \mathrm{~Hz}$, precise rates were not listed), whereas the sentence in English has a smaller range in pitch $180 \mathrm{~Hz}$ to $271 \mathrm{~Hz}$ ). Most sampled declarative sentences were similarly small in pitch range.

Pitch analysis revealed more similarities in the pitch contour of yes / no questions in English and in Georgian. The analysis from Jun et al. (2007) revealed a high pitch on the main verb of a simple yes / no question, see Figure 7. The intonation is particularly expressive at the main verb (is washing / bans). A similar pitch was found in participants' utterances in English, see Figure 8. The expressive pitch contour can be seen on the second syllable of the main verb (going). Note that this example reveals a strong use of elision. 


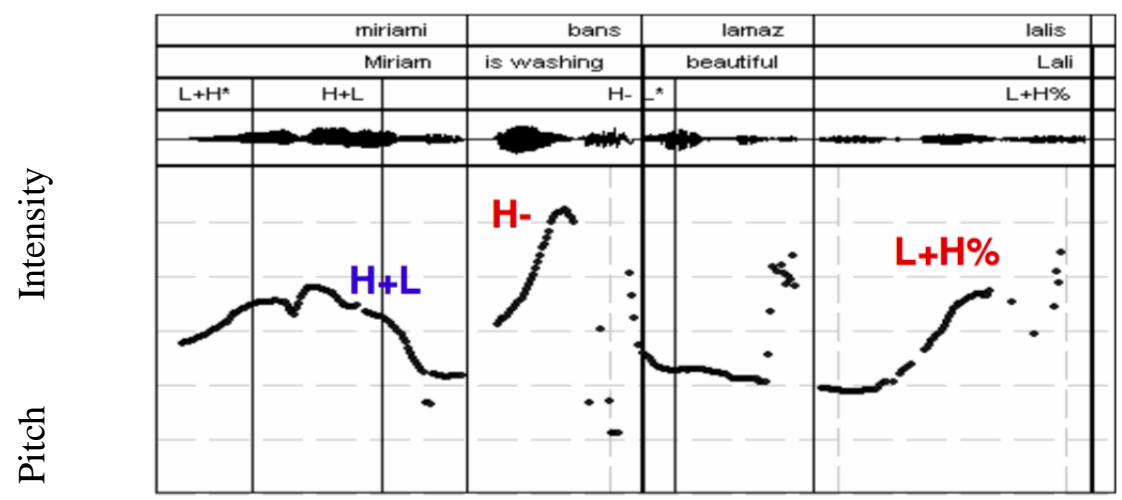

Time

Figure 7. Georgian yes / no question with rising and falling intonation on main verb and rising terminal intonation (Jun et al., 2007, p. 11)

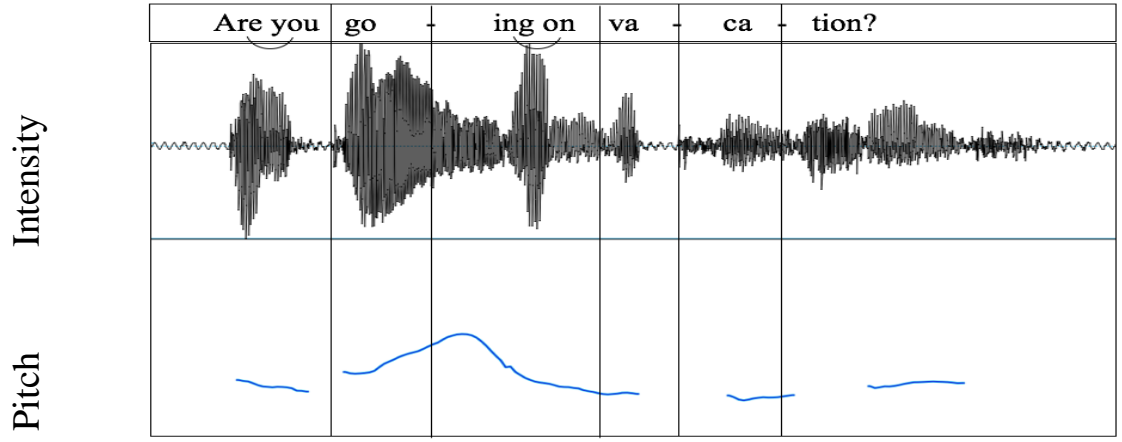

Time

Figure 8. Participant yes / no question in English with small rising intonation on main verb.

Word stress analysis and comparison with Georgian phonology revealed similarly that errors in word stress were only sometimes linked with the Georgian word stress system. In Figure 9, two words are compared. In Georgian, the first syllable is stressed in the four syllables of cakitxebs. The second example is from a study participant who made an error with word stress in a five syllable word, enthusiastic. While the rhythm of the word indicates a slowing on the -a- syllable, the waveform shows us that more intensity was placed on the first syllable.

Four syllable word (From Jun et al. (2007) Five syllable word from participant

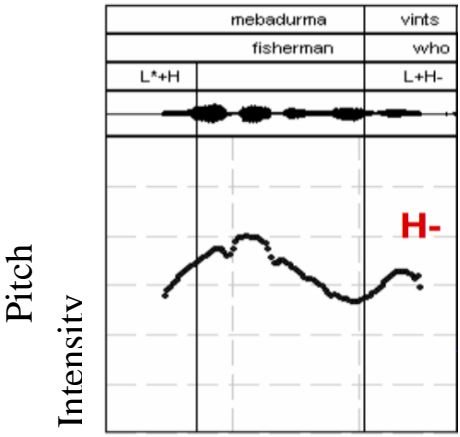

Time

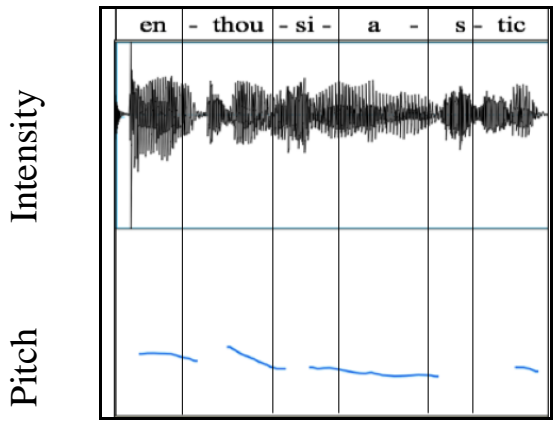

Time

Figure 9. Side-by-side comparison of word stress in Georgian and uncommon word stress in English by participant. Graph on left from Jun et al. (2007, p. 9). 
However, there were several examples of misplaced word stress that did not follow Georgian phonological examples. In Figure 10, the participant places the stress on the penultimate syllable, a feature not found in any Georgian phonological studies reviewed for this study.

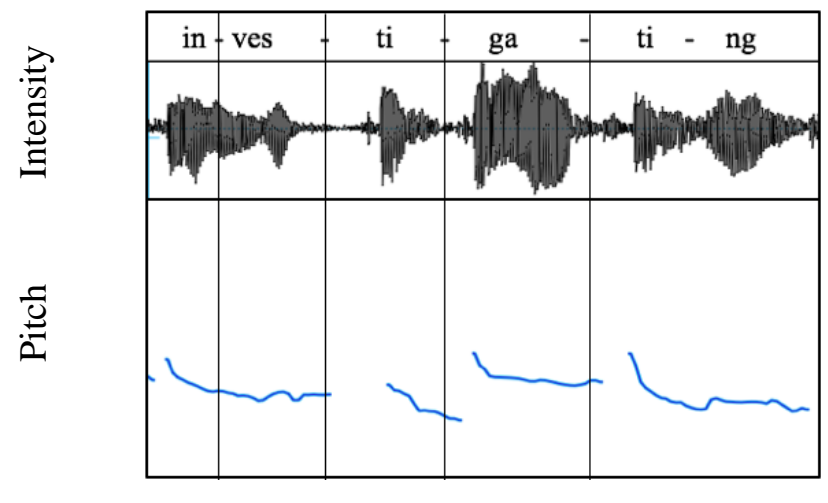

Time

Figure 10. Example of participant word with uncommon stress on penultimate syllable.

\section{Discussion}

This study set out to test the impact of using Praat to train to prosodic features: intonation and word stress. These features were chosen because of the research that has been done on them in the participants' native language, which would allow for comparison and analysis of L1 - L2 transfer. Data collected in this study was also compared to Georgians speaking in Georgian from other studies (Borise, 2017; Jun et al, 2007; Skopeteas et al., 2009).

\section{Intonation}

Declarative and information (wh-) question types intonation contours were found to increase in accuracy with Praat training. However, polar (yes / no) questions were seen to have decreased in quality. Inferential statistics did not find a significant difference. This is likely due to the limited sample size of these questions and therefore this construct should be retested in a future study with more participants and larger tokens of question types. Previous studies using explicit visual information for intonation training has found an impact of the training on learner utterances (Gorjian et al., 2013), indicating that the results for declarative and polar (yes / no) questions may be more accurate than the overall comparison.

Furthermore, it may be possible that some types of intonation are deemed more important by L2 learners or are more learnable. This may be particularly true as many young speakers of English use a high rising tonal terminal as a part of a sociolect called uptalk (Fletcher, Grabe, and Warren, 2006; Ritchart \& Arvaniti, 2014). Without further investigation into the types of input the learners are encountering, it is impossible to know if this relatively new wave of intonation contour may be interacting with their production. Indeed, there are legitimate arguments made about the value of imposing specific intonation contours in EFL settings (Jenkins, 2000). However, there is still value in the topic in terms of understanding NSEs and for learners who wish to acquire a specific accent.

The Georgian intonation system features seemed to transfer to English to some extent. As seen in Figures 5, 6, 7 and 8, main verb intonation was often altered as compared to adjacent pitches. However, the examples found in the data did not match the peak intonation found in the Georgian examples. This may be for several reasons. The utterances may have been neutral, without the focus of a specific part of the declarative or question. Alternatively, the learners may have not recognized that part of the segment as the main verb. Finally, it is possible that the learners do not have enough mastery of the language to use intonation to express a 
pragmatic meaning. Future studies in this area should strive to collect natural speech and examine focus in those situations.

\section{Word Stress}

The word stress analysis of this study revealed a decrease of word stress errors after the treatment. Inferential statistics found a significant difference and the effect size was calculated at eta $^{2}=0.74$, a medium to strong effect size. Despite the small number of participants, the texts analyzed included 1009 words, a relatively robust number. Previous studies have investigated the acquisition of word stress and have also confirmed that interventions can have an impact (e.g., Derwing \& Rossiter, 2003). While there is evidence to support the efficacy of word stress instruction, there are many questions as to which word stress standards should be taught.

In the light of sociolinguistic studies in variation of word stress (Cutler, 2005), there are variations in word stress not only in geography, but across age and socioeconomic variables. Research in English as a Lingua Franca have also found that word stress is less important than other features for comprehension of NNSEs to NNSEs (Jenkins, 2000). However, studies such as Field (2005) indicate the importance of word stress in intelligibility amongst highly proficient NNSEs. As the verities of English spoken by NSE and NNSE groups continue to evolve, it will be important to understand the role word stress plays in intelligibility in terms of the context of learners as well as their goals. The present study did not investigate intelligibility by listeners, however it lays the groundwork for understanding the possible variation amongst Georgian NNSEs.

These results have implications for teachers and learners. The results of the second research question support the empirical body of evidence that teachers, as promoted in Wilson (2008), can use Praat as part of the pronunciation teaching process to give visual, explicit feedback to learners as they do controlled practice on specific phonological features. Particularly, those may be effective when using technology. For learners, the ability to see and attempt to match phonological features from a target visual to a Praat-generated visual of one's own speech may be an approach to self-study in improvement of pronunciation.

The limited number of participants in this study poses several issues for the generalizability and the impact of these findings. With four participants, there is little generalizability in the results. Rather, the findings in intonation, word stress, and Georgian phonological influence in Georgians speaking English may guide future studies.

In the coming years, there is expected to be a continuation of technology that assists learners, some of which may target the areas of perceiving and producing sounds in a foreign language. While this technology could make it even easier for learners to understand their phonological output, there is a large question looming about which norms should be targeted. Promising research in computational linguistics and English as a Lingua Franca will likely lead the way in describing, in detail, phonological semantic mappings, the boundaries of intelligibility in variation, and therefore, the features of phonology that must be prioritized when designing content for learners. 


\section{References}

Alkhazishvili, 1959 - Alkhazishvili, A. (1959). Porjadok slov i intonacija v prostom povestvovateljnom predlojenii gruzin skogo jazyka [Word order and intonation in simple extended sentences in Georgian]. Phonetics (Moscow), I, $367-414$.

Boersma, 2001 - Boersma (2001). Praat, a system for doing phonetics by computer. Glot International, 5 (9), $341-345$.

Bond, 1999 - Bond, Z. (1999). Slips of the ear: Errors in the perception of casual conversation. San Diego, CA: Academic Press.

Borise, 2017 - Borise, L. (2017). Prosody of Focus in a Language with a Fixed Focus Position: Evidence from Georgian. In 34th West Coast Conference on Formal Linguistics (pp. 89 - 96). Cascadilla Proceedings Project.

Butskhrikidze, M. (2002). The consonant phonotactics of Georgian. Utrecht, Netherlands: LOT.

Butskhrikidze, M. (2016). On the word level accentuation in Georgian. The South Caucasian Chalk Circle, Paris, September 24, 2016.

Celce-Murcia, M., Brinton, D. M., \& Goodwin, J. M. (2010). Teaching pronunciation hardback with audio CDs (2): A course book and reference guide. Cambridge University Press.

Cohen J. (1988). Statistical Power Analysis for the Behavioral Sciences (2nd ed.), Hillsdale, NJ: Erlbaum.

Cutler, A. (2005). Lexical stress. In D. B. Pisoni and R. E. Remez (Eds.), The handbook of speech perception, (pp. 264 - 289). Blackwell: Maiden, MA.

Derwing, T. M. \& Munro, M. J. (1997). Accent, intelligibility, and comprehensibility: Evidence from four L1s. Studies in Second Language Acquisition 19, 1 - 16.

Derwing, T. M. \& Rossiter, M. J. (2003). The effects of pronunciation instruction on the accuracy, fluency, and complexity of L2-accented speech. Applied Language Learning 13,1-18.

Field, J. (2005). Intelligibility and the listener: The role of lexical stress. TESOL quarterly, 39 (3), 399 - 423.

Flege, J. E. (1984). The detection of French accent by American listeners. Journal of the Acoustical Society of America 76, 692 - 707.

Fletcher, J., Grabe, E., \& Warren, P. (2006). Dialects of English: the High Rising Tune. Prosodic typology: The phonology of intonation and phrasing, 1, 390.

Fries, C. (1964). On the intonation of 'yes-no' questions in English. In D. Abercrombie (Ed.). In Honour of Daniel Jones (pp.242 - 254). London: Longman.

Gilbert, J. B. (1978). Gadgets: Non-verbal tools for teaching pronunciation. CATESOL Occasional Papers, 4, $68-78$.

Gorjian, B., Hayati, A., \& Pourkhoni, P. (2013). Using Praat software in teaching prosodic features to EFL learners. Procedia - Social and Behavioral Sciences, 84, 34 - 40.

Grosjean, F., \& Gee, J. (1987). Prosodic structure and spoken word recognition. Cognition, 25, 135 - 155.

Hancock, M. (2003). English Pronunciation in Use. Cambridge University Press.

Jenkins, J. (2000). The Phonology of English as an International Language. Oxford: Oxford University Press.

Jun, S. A., Vicenik, C., \& Lofstedt, I. (2007). WPP, No. 106: Intonational Phonology of Georgian. Working Papers in Phonetics, 106, 41 - 57.

Lane, L. (2005). Focus on Pronunciation.

Levis, J. M. \& Pickering, L. (2004). Teaching intonation in discourse using speech visualization technology. System, 32, $505-524$. 
Munro, M. J. \& Derwing, T. M. (1995). Foreign accent, comprehensibility, and intelligibility in the speech of second language learners. Language Learning 45, 73 - 97.

Newman, S. S. (1946) On the Stress System of English. Word, 2 (3), $171-187$.

Ogden, R. (2009). An introduction to English phonetics. Edinburgh University Press.

Ritchart, A. \& Arvaniti, A. (2014). The form and use of uptalk in Southern Californian English. In Proceedings of Speech Prosody, 7, 20 - 23).

Roach, P. (1982). On the distinction between "stress-timed" and "syllable-timed" languages. In D. Crystal (Ed.), Linguistic Controversies (pp.73 - 79). London: Edward Arnold.

Seattle Learning Academy. (2016). Pronuncian.com: American English pronunciation. Website. https://pronuncian.com.

Skopeteas, S., Féry, C., \& Asatiani, R. (2009). Word order and intonation in Georgian. Lingua, 119 (1), 102 127.

Student. (1908). The probable error of a mean. Biometrika, $1-25$.

Wilson, I. (2008). Using Praat and Moodle for teaching segmental and suprasegmental pronunciation. In Proceedings of the 3rd international World CALL Conference: Using Technologies for Language Learning (World CALL 2008) (pp. 112 - 115).

Zielinski, B. W. (2008). The listener: No longer the silent partner in reduced intelligibility. System, 36, $69-84$. 